\title{
Medical Image of the Week: Kartagener Syndrome
}

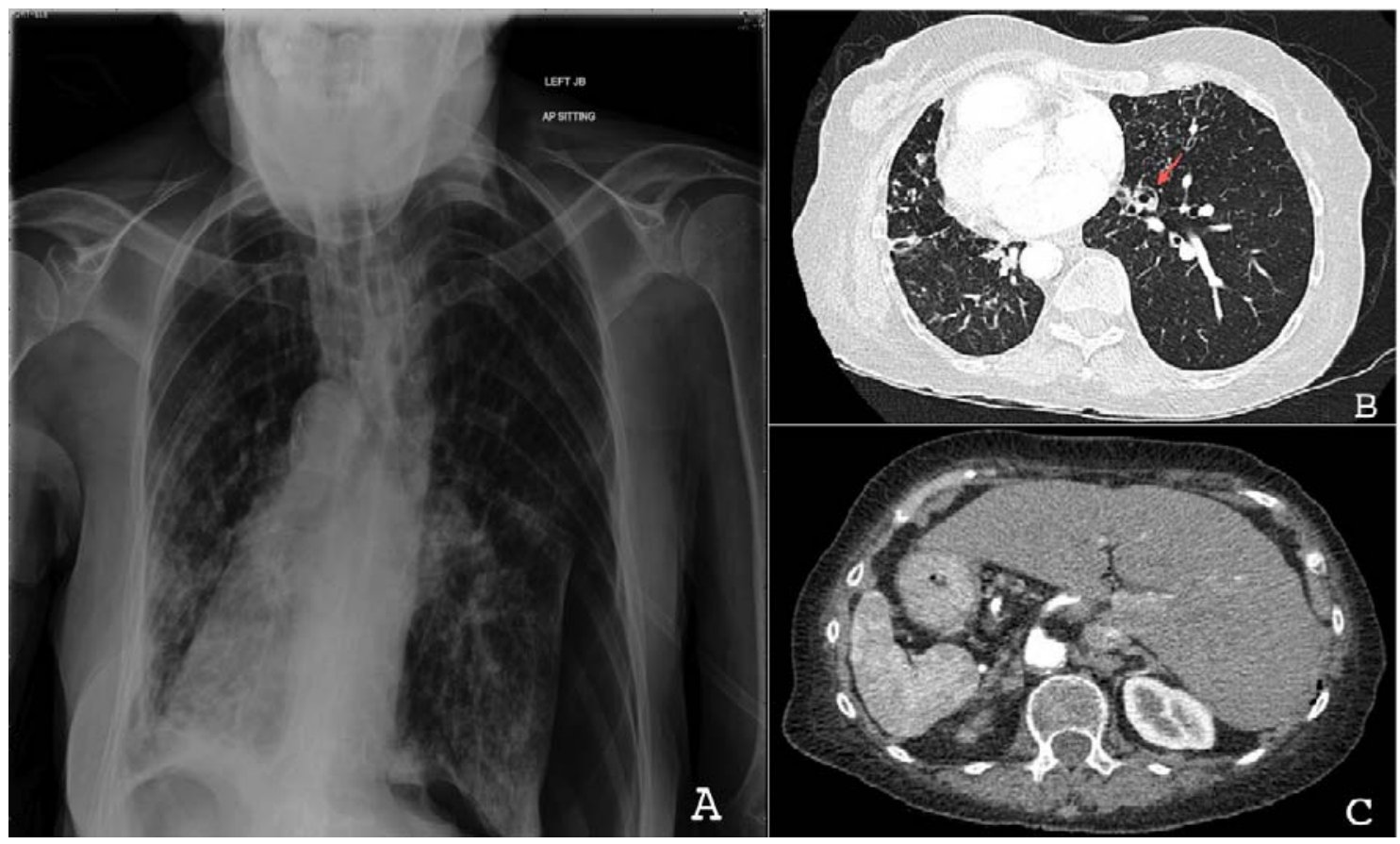

Figure 1. Panel A: AP chest x-ray showing dextrocardia with left sided pneumothorax. Panel B: CT Chest lung windows showing diffuse bronchiectasis. Panel C: CT Abdomen consistent with situs inversus.

A 65-year-old woman presented with 7 days of productive cough and the new onset sharp central chest pain. She has a known history of chronic sinusitis and COPD after being a 50 pack-year smoker. On examination, her blood pressure was 116/70 with a heart rate of 86 (sinus rhythm) and oxygen saturations were $93 \%$ on $4 \mathrm{~L} / \mathrm{min}$ by nasal cannula. She had bilateral expiratory wheezes with reduced air entry on the left side.

An AP chest x-ray revealed dextrocardia with a left sided tension pneumothorax (Figure 1A). Our patient was stabilized with an urgent chest tube insertion and taken for a CT chest and abdomen. CT chest indicated diffuse bronchiectasis (Figure 1B, arrow) with a CT of the abdomen showing reversal of major abdominal organs (Figure 1C).

First described in 1933, the triad of chronic sinusitis, bronchiectasis, and situs inversus is classic for Kartagener syndrome (1). Otherwise known as primary ciliary dyskinesia, it is an autosomal recessive disorder affecting the dynein motor protein on microtubules. Ciliary dysfunction from an embryonic stage is the underlying cause for $50 \%$ of patients with situs inversus (2). Ongoing difficulties clearing mucous and secretions from abnormal ciliary movements accelerates 
the development of rhinosinusitis and bronchiectasis (3). Fertility is also a common concern with most males being infertile and females having a lower likelihood of successful pregnancy (4).

Confirmatory testing requires electron microscopy to determine ultrastructure and high-speed video microscopy to determine abnormal movement of cilia (4). Longterm management involves control of respiratory complications with regular spirometry and pulmonary follow up.

Debraj Das, MD

Department of Medicine

Faculty of Medicine and Dentistry

University of Alberta

Edmonton, $\mathrm{AB}$, Canada

\section{References}

1. Kartagener M. Zur pathogenese der bronchiectasien. I Mitteilung: bronchiectasien bei situs viscerum inversus. Betr Klin Tuberk. 1933; 83:498501.

2. Noone PG, Leigh MW, Sannuti A, et al. Primary ciliary dyskinesia: diagnostic and phenotypic features. Am J Respir Crit Care Med. 2004; 169:459-467. [CrossRef] [PubMed]

3. Bush $A$, Cole $P$, Hariri $M$, et al. Primary ciliary dyskinesia: diagnosis and standards of care. Eur Respir J. 1998; 12:982-988. [CrossRef] [PubMed]

4. Knowles MR, Daniels LA, Davis SD, et al. Primary ciliary dyskinesia. Recent advances in diagnostics, genetics, and characterization of clinical disease. Am J Respir Crit Care Med. 2013; 188:913-22. [CrossRef] [PubMed] 